\title{
On Distributional Features of Adverbial Modifier of Manner in Typologically Different Laguaes: A Case Study
}

\author{
Mirzayeva Intizar Gahraman*
}

Azerbaijan University of Languages, Baku, Azerbaijan

Corresponding Author: Mirzayeva Intizar Gahraman, Email: inamirzayeva05@mail.ru

\begin{tabular}{l} 
ARTICLE INFO \\
\hline Article history \\
Received: September 16, 2017 \\
Accepted: November 24, 2017 \\
Published: December 30, 2017 \\
Volume: 8 Issue: 6 \\
Advance access: December 2017 \\
\hline Conflicts of interest: None \\
Funding: None \\
\hline
\end{tabular}

Key words:

Sentence,

Sentence Member,

Adverbial Modifier,

Distribution of Sentence Members,

Place of Adverbial Modifier of Manner

in the Sentence

\begin{abstract}
The study aims to analyze the distributional features of adverbial modifier of manner in two languages that are typologically and genealogically different: English and Azerbaijani. Although the issue has been focused in these languages separately from various angles including semantic, syntactic and prosodic perspectives, there is a gap in the domain of comparative studies. In this regard, syntax is of special importance. Syntactic analysis reveals that in the both languages sentence members are not distributed randomly. In other words, their distribution within the sentence is regulated by certain rules. Each of the sentence members, entering the sentence structure in the syntagmatic order, establishing coordination with sentence members coming before or after it, turns to the bearer of the intended semantic or grammatical functions. Analyses of grammatical forms of the sentences in the English and Azerbaijani sentences show that alongside the universal features which are common for the grammatical forms in sentences of each language, these languages possess distinctive features as well.
\end{abstract}

\section{INTRODUCTION}

\section{Adverbials: A Brief Literary Review on Focal Points}

Research on adverbials is not new although interest in them never faded. In fact, the issue has widely focused in various languages and perspectives. Interest in them has ignited visà-vis new approaches to linguistics and grammar. In general, research on adverbials can be grouped as those that consider the issue comparatively and those which focus on the issue from various angles referring to specific languages. In this brief literature review section, some seminal views will be touched upon.

One of the perspectives in research in adverbials is the comparative approach where preference is given to discrete and common features. For instance, Chládková (1979) examines the Czech adverb of manner and its English and German opposite numbers from the point of view of functional sentence perspective with emphasis on the semantic and grammatical structures. In the same vein, Duskova (2002) focuses on syntactic constancy of adverbials assuming that "syntactic structure is hierarchically subordinate to the information structure (functional sentence perspective, FSP...) insofar as the latter is governed by the principle of end focus, which is assigned universal validity" (p. 111). The languages involved here are English and Czech.

On the other hand, as it was mentioned above, research on adverbials is devoted to various approaches or perspectives. For instance, Povolná (2000) deals with spatial and temporal adverbials of all possible realization types and the ways in which they cooperate with finite verb phrases in order to express what is called the spatio-temporal setting by applying Functional Sentence Perspective (FSP). However, Haider(2000) considers the topic in terms of their structural identification, interface conditions and serialization patterns. In the same vein, Tenny (2000) focuses on certain syntactic and semantic elements of event structure that are crucially referenced or invoked by certain types of adverbs.

Literature review also shows that pragmatic approach to adverbials can also produce interesting results. In this regard, there is a need to mention Eckart (2003) who considers manner adverbs and information structure placing emphasis on the pragmatic effects of word order variation in German. Koktova(1986) takes the issue further to consider sentence adverbials in the framework of Functional Description even 
beyond pragmatics. In her book, the author presents empirical arguments in favor of a joint syntactico-semantic treatment, within the framework of a functional generative description, of a range of adverbial expressions which should be viewed as belonging to a single, lexically heterogeneous but functionally homogeneous, class exhibiting scoping properties and functioning as 'complementation of attitude'(CA). The author also mentions that these CA-expressions do not only share their underlying functional properties but also certain surface-syntax properties. A similar approach has been applied by Hengeveld (1997) who considers the issue in the framework of Functional Grammar.

Quite a difference stance was taken by Fillmore(1994) who, having analyzed various views, speaks of the need for mechanisms "for projecting the valence set of a verb into the compliment set of a VP" and the need for "context-sensitive ways of allowing any way of a larger number of circumstantial adjuncts to be added to sentences" (p. 170).According to Von Geuder (2000), on the other hand, certain fundamental concepts (e.g. the notion of 'manner) were undefined and unclear in a way that could not be resolved simply by appealing to subevents" (p. iii). Moreover, "the same lack of a precise understanding also seemed to infect the whole notion of "predicate of events" as applied to modifiers: Neo-Davidsonian semantics seemed to be built on dim intuitions as to the precise content, character, and scope of these notions" (p. iii). Therefore, the author proposed that "for modifiers, event predication can indeed be something that is lexically derived, and is thus not as monolithic and inscrutable as the neo-Davidsonian notation would make us believe..." (p. iii).

The approach taken by Yang(1999) differs significantly from other researchers. The author considers the issue from a computational perspective. The author views adverbials as modifiers of verbs by linguistic definitions in which they are characterized by modifying systems (functions). Different types of relationships between verbs and adverbs (adverbials) are presented and modeled. Unlike the relations between adverbs and adjectives, which are only static maps, the relations between verbs and adverbs (adverbials) have very rich interpretations in different contexts. The study, computational verb systems with adverbs are used to preprocess speech signals for speech recognition.

Among the perspectives taken in research on adverbials, one can also mention Yokota (2011) who aims to "explore the division of labor between the syntactic, semantic and discourse constraints involving the adverbial modification" and offers "an explicit account for the apparently elusive paradigm, ascribing such properties to the dual analysis of complements and adjuncts for the correct characterization of manner adverbs in the language" (p. 386). The author also shows that "the proposed analysis can be easily integrated into a Lexical-Functional Grammar (LFG) formalism" (p. 386). However, Pezatti(2007) considers the issue from the perspective of ordering of representational level by applying the Functional Discourse Grammar theoretical model. The author shows that "the order of modifiers of the Representational Level in spoken Brazilian Portuguese is determined by scope relations according to the layers of property, state-of-affairs and propositional content" (p. 293). According to the author, "this kind of distribution indicates that, far from being free-ordered as suggested by traditional grammarians, modifiers have a preferred position determined by semantic relations that may be only changed for pragmatic and structural reasons" (p. 293).

Distributive features of adverbials have been focused on by some researchers as well. For instance, López (1995) "offers an account of the distribution of adverbial phrases in English based on two main assumptions: a) that adverbs can be characterized as logical predicates which may take one or two arguments to saturate their reference and b) that the eventual distribution of adverbs is crucially conditioned by the constituent structure of the sentence.e propose that the traditional classification of adverbs as verbal or sentential modifiers must be extended to include another class: that of the adverbs which are predicated of one of the functional categories which, according to the Principles and Parameters Theory, appear in the sentence" (p. 181). The author argues that "adverbs are located in any position from which they may comply with their lexical requirements, and we explore the empirical consequences which follow from this fact" (p. 181). In the similar vein, Diessel (2001) "examines the ordering distribution of main and adverbial clauses in crosslinguistic perspective" (p. 433). Using a representative sample of forty languages, the author shows that the ordering of main and adverbial clauses correlates with the position of the subordinator in the subordinate clause. In languages in which adverbial clauses have a final subordinator, adverbial clauses tend to precede the main clause, whereas in languages in which adverbial clauses are marked by an initial subordinator, adverbial clauses commonly occur in both sentence-initial and sentence-final position. In the latter language type, the position of an adverbial clause varies with its meaning or function: conditional clauses precede the main clause more often than temporal clauses, which in turn are more often preposed than causal, result, and purpose clauses". Diessel (2001) explains the distributional patterns "in terms of competing motivations; it is suggested that they arise from the interaction between structural and discourse-pragmatic factors" (p. 433). Similarly, Virtanen (2008) mentions the fact "Adverbials of manner are often regarded as prototypical; yet, there is important variation within the postulated category and a great deal of fuzziness at the edges of this multifaceted theoretical notion" (p. 271). Therefore, the author attempts to draw "a line between two broad categories: 'manner' and 'manner plus', i.e. semantic blends" (p. 271). In fact, informed by text and discourse linguistics, the author focuses "on linearization in written English - in particular, on the strong motivations needed for a non-typical, syntactically marked placement of manner (plus) adverbials at the outset of a clause or sentence, in what is generally also a stylistically dispreferred position" (p. 271).

A study carried out by Toratani (2007) on the materials of the Japanese language is original in a sense that it "offers a Role and Reference Grammar (RRG) account of the syntax of adverbial mimetics (onomatopoeias and ideophones), which constitute a subset of manner adverbs in Japanese" 
(p. 311). More specifically, the study aims at examining "which syntactic unit(s) a mimetic can modify in the layered structure of the clause; nucleus, core, or clause" (p. 311). The author argues that "Japanese manner adverbial mimetics are likewise categorized dichotomously but the unit they can modify is one layer inward: i.e. the core or the nucleus" (p. 311).

Our concise literature review indicated that research on the use of adverbials in printed matewrials can also be witnessed. In fact, Hasselgård (2010) discusses the use of adverbials in English referring to printed materials. The author defines adverbials as clause elements that typically refer to circumstances of time, space, reason and manner which cover a range of meanings. Having described the frequency ofmeaning types and discussed the reasons for selecting positions arrives aet a conlusion that thatthe use of adverbials differs across text types. As the author mentions, the Adverbial usage is often linked to the general build-up of a text and can reflect its content and purpose. The author also identifies a challenge for the classification of adjuncts, and also highlights the fact that some adjuncts have uses that extend into the textual and interpersonal domains, obscuring the traditional divisions between adjuncts, disjuncts and conjuncts.

Finally, there is also a study which considers the isse from a pedagogical perspective. For instance, Zareva (2009) aims "to identify specific functions L1 and L2 college students attributed to circumstance adverbials (the most frequently used adverbial class in the data) in relation to packaging the informational content of their presentations and their perceived level of formality of the genre" (p. 55). Her analysis of circumstance adverbials was based on L1 and L2 corpora of student presentations. She arrived at a conclusion that" the L1 presenters seemed to perceive the academic presentation as an opportunity not only to present information in an informal way, but also to interact with the audience and keep it involved in their presentations" (p. 55). It was also found out that unlike L1 presenters, "the L2 presenters seemed to be preoccupied with the informational content of their presentations, frequently to the exclusion of their peers from the process of information negotiation, which suggested a more formal and informative function they attributed to the presentation as a speech event than the native speakers" (p. 55).

Thus, even this brief literature review shows that the interest in adverbials not only fades, it gains more impetus. In fact, there seems to be a shift from a 'pure' classical approach to a more empirical or 'computational' one. Moreover, it is evident that comparative studies may help to have better insights into the issue. From this viewpoint, it would be interesting to revisit the issue by involving such typologically and genealogically different language as Azerbaijani and English.

\section{Adverbial Modifier of Manner: Distributive Features}

Communicative process is not realized by separately - taken isolated lexis units, but it is realized by syntactic units, possessing different semantic and functional peculiarities. Among these syntactic structures sentences are more distinguished by their frequent usage and as to their peculiarities for expressing different thoughts. In the history of development of the language investigation of grammatical and intonational peculiarities of sentences, distinguished among the other syntactic units, acting as the main unit of the syntactic structure of the sentence has always made the scholars think of this problem, and in the modern linguistic too, this problem has always been distinguished with its actuality. Both in English and in Azerbaijani languages, the features, characterizing sentences, are applied in different field of sentences (semantic, syntactic, phonetic, etc.). Among these fields the field of syntax is of special importance. As Smirnitskiy (1957:50) noted, syntax is a field of science studying word combinations, including the rules of setting up a sentence by these word combinations. Pointing out that syntax consists of two parts, he writes that the first part is the field of science, learning the grammatical coordination of words in a sentence or in word combinations, but the second part is a field of science learning the rules of setting up sentences. However, Shendels (1952:246) pointed out the combination of 3 units within syntax. These are the followings:

1. Sentence members.

2. Word combinations.

3. Sentence.

Certainly among the pointed out view-points sentence can be accepted as a main unit, because the first two units (sentence members and word combinations) are subordinated within the sentence in which they are used. For e.g. She angrily left the room./O, otağl actqla tork etdi.

This structure being a unit as a structure, combines several sentence members and word combinations in it. In the sentence four sentence members (subject, predicate, object and adverb) intended for the expression of a thought have been coordinated semantically and syntactically. At the same time the following combinations being in semantic coordination in this sentence have found their expressions:

1. He left

2. He left the room

3. He left the room angrily.

All this helps the formulation and expression of the sentence $(O$, ota $\breve{g} l$ acıqla tork etdi - He left the room angrily). In this regard, Musayev (1996) highlighted the role of a sentence in communication and noted that in the use of language as a means of communication, participation of a sentence is one of the obligatory conditions. As to him, the communicativity, being a major condition is possibly realized only within a sentence and creates possibilities for the language to be used as a means of communication (p. 353). Language unit, which we use as a sentence to-day and try to study all its peculiarities, represents the main object of investigation of syntax. According to $\mathrm{Mu}-$ sayev (1996) among the features that define a sentence are (a) expressing relative thoughts; (b) possessing a certain syntactic structure; (c) possessing a certain type of intonation; (d) expressing modality. Referring to these criteria, Musayev (1996) determines sentence as a units which possess certain grammatical structures and intonation, which express modality, express relatively a complete thought (p.355). 
What concerns the criterion of 'expressing relative thoughts', it can be said that not all sentences express a complete thought. Confer the following sentences: Very quietly she opened the door//O qapını çox sakitcə acdl. Analysis shows that hearer does not easily understand this sentence in the isolated form from the text, because context is uncertain. In the sentence personal pronoun "she" ("o") can be explained "who this pronoun belongs to" only by the help of presupposition and which is not quite clear again. It is also not clear what the object (door - qapl) belongs to, why the manner of action is expressed in this form, in what space and time action takes place, all these are not clear for the listener either. This gives us possibility to say that in the speech act, in the syntagmatic level sentences in a chain like form are in coordination with one another. Veysalli (2003:33)analyzing the character features of sentences notes that words express events too, but sentences express events and notions by the mutual coordination and influence of objects in the frame of the language structure.

Sentence is not a conglomeration of words. It is possible to reveal the meaning of a concrete sentence, under the condition if we take a sentence as an array of word forms which reflect objective reality and which mutually interact semantically and grammatically with one another, which in itself means the determination of semantic characterization of the realized structure.

Azerbaijani linguists Abdullayev, Seidov and Hasanov (1972) pointed out distinctive features of sentence differing it from the other syntactic units as follows: "A sentence being semantically and grammatically completely formulated manner of expression, by expressing one thought is distinguished among the other syntactic units and acts as the main unit of the syntactic structure of the sentence" (p.132). In fact, the idea of sentence as a main unit of sentence can be accepted. The same is not true with the idea that a sentence is a unit to express a complete thought. A sentence could rather be identified as a unit which expresses "relatively complete thoughts". In a sentence 'a completed thought' bears a relative character. That's why the distribution of sentences within a text, as to certain requirements, following one another in a text and completing one another are linked relatively with the unity of thoughts which they express. The thought "on the expression of a sentence relatively a complete thought" has found its reflection in Budaqova (1963). According to the author, "A sentence, expressing relatively a completed thought is characterized by a number of features, determining its structure, meaning unity and its independence" (p.110). The author also mentioned that each uttered sentence possesses intonation, indicating complete information, predicativity and modality.

Analyses of grammatical forms of the sentences in the English and Azerbaijani sentences show, that alongside the universal features which are common for the grammatical forms in sentences of each language, these languages possess self-belonging, distinctive objective laws as well. Some other linguists consider a sentence as a unit possessing completion of thought and independence in the speech act, but language materials do not complete the expressed thought, because they do not possess the only completeness.

Concerning syntax Chomsky (2006:152) implies grammar as the net of all the sentences in a text which possess or do not possess the completion. The author points out that theoretically in each sentence the quantity of grammatically correct sentence are in an endless number but in order to distribute these sentences in endless number, we possess rules being in numbers having certain ends, by the help of which these numberless sentences are created. From this idea it becomes clear that the investigator analyzes the sentence as a unit of speech. Most of the linguists unanimously support the idea expressing "in the center of all the means serving the creation of intercourse as a complicated process, mainly stands a sentence". Just for this reason in each language sentence being a central unit of syntax expresses most important features of the language. It is clear, that without taking some situations into consideration (as in the case when deaf and dumb people are in intercourse) people carry out communicative functions by means of sentences. The structural peculiarities of the used sentences not always are the same. The variety in the expression of these units, depending on the theme, the expressed thought on how well the speaker is aware of the communicative means of the speaker, on the stylistic features of the speaker, on the attitude of the speaker to the expressed idea, in the spiritual atmosphere of the participant of the communication etc. change and bear varieties character. For e.g. We worked without ceasing//Biz dayanmadan işladik. Certainly this thought can be expressed in simpler forms, such as (we worked//biz işladik)or in the form of modification (Biz saylo işladik//Biz yorulmadan işladik//We worked hard//We worked without getting tired) etc. In this process cognitive preparation of both the speaker and listener must be taken into consideration. In the syntactic level it depends on which function the language unit carries out in the composition of a syntactic whole with which it becomes in coordination. All these factors influence on the structural features of the realized sentence. The fact that such a form of expression is characteristic for each of sentences, has been noted in the linguistic literature.

In every language, including the English and Azerbaijani languages the basis of the language composes independent syntactic functions linked with one another semantically and grammatically and word combinations. Such kinds of word combinations in syntax are called sentence members. In order to cognize the importance of sentence members, as it has been noted in the linguistic literature, it is necessary to determine first of all their syntactic functions, means of their expressions, the means of syntactic coordination among them, their structures, their syntactic issues and their inner types. As it is in the English language, in the Azerbaijani language as well sentence members are divided into main members of sentences and secondary members of sentences. In the both languages, in the construction of a sentence in the expression of thought it is important that two sentence members should take parts. These two members are called the main sentence members. For e.g.: I am reading//Mon oxuyuram. These are in both languages simple sentences, consisting of 
two members and have been built up on $\mathrm{S}+\mathrm{P}$ model. The other sentence members serving the expression of the main thought are the secondary sentence members. These are the following members: object, attribute and adverb.

Smirnitski (1957) considers the reason why these members are called the secondary sentence members, sentences can be established even without them and a thought is expressed. For e.g.: I accepted the gift thankfully//Man mamnuniyyatla hadiyyani qabul etdim. As Smirnitski (1957) points out, unless we use the word 'thankfully' carrying out the function of adverb of manner, the sentence shall remain as a sentence (I accepted the gift). Even in this sentence the word gift can also be abridged (I accepted...), the core of the contents remains, which can be expanded any time and by any member of the sentence. But if we do not use one of the two remaining sentence members, sentence loses its meaning (p.165). Similar cases can be met for the Azerbaijani language as well. For e.g. In the sentence//Man hadiyyani qabul etdimif we do not use the object of the sentence (hadiyyani) and the adverb (minnotdarliqla), the core of the sentence is not affected. Moreover, even without the secondary members, the sentence protects its possibility of expressing a thought (Mon qabul etdim). But if we miss the usage of one of the main members of the sentence (subject or predicate) in the structure of the sentence, then the sentence loses its meaning. For e.g.: Man hadiyyani minnatdarliqla.Here there is not a complete thought and it is not expressed. As English and Azerbaijani languages represent language with different systems, here too, distinction shows itself. In the English language in such type of sentences, while the usage of subject is formally obligatory, in the Azerbaijani language, even if the formal subject is not used, it is possible to restore the subject as to the endings in the end of the verbs which indicate persons. For e.g.:

1. Mən hədiyyəni minnətdarliqla qəbul etdim.

2. Hədiyyəni minnətdarlıqla qəbul etdim.

3. Mən hədiyyəni minnətdarlıqla.

It becomes clear from the explanation, that the third model as to the linguistic laws of the Azerbaijani language is not operative. In the second case, the doer of the action "Man" the subject of the sentence, though is not used, but it becomes clear as to the ending which the verb accepts "-im". The secondary sentence members mainly subordinate to the main sentence members group around them. Both in English and Azerbaijani languages adverbs, being in coordination with predicates, explain the predicate from different features. They explain//manner, place, time, quantity etc. Nine types of adverb have been identified in the Azerbaijani language: (a) adverb of manner; (b) adverb of place; (c) adverb of time; (d) adverb of cause; (e) adverb of purpose; (f) adverb of quantity; (g) adverb of degree (grade); (h) adverb of condition; (i) mixed - adverb of concession. In fact, the same types have been indicated in the English language. In this article, the emphasis is placed on the adverb of manner. The analyses of language materials show us, adverb of manner itself explains the actions from different aspects. For e.g.:

1. Sophie was moving uncomfortably in the park//Sofi parkda narahat hərəkət edirdi (manner of execution of the action)
2. He seemed doomed to liberty//O, azadlıq məhkumu kimi görünürdü (comparison of the action)

3. Carefully she touched the child//O qayğıyla uşağa toxundu (quality of the action)

It becomes clear from the examples that in the both languages the manner of the action is expressed. The manner of the action belonging to adverb is used within the verb group. In the first sentence it explains the manner of action, in the second sentence; it explains that the action is carried out comparatively, while in the third sentence it explains, in what quality the action has been executed.

Besides, another feature also becomes clear that in the English and Azerbaijani languages, depending on the thought which is being explained, in the both languages simple sentences, depending on the participation of sentence members possess different structural peculiarities. Namely, the structure of a sentence is formulated on the basis of thought, which is expressed. Like other secondary members and types of adverbs, sentences with adverbs of manner are also considered as simple extended sentences. For e.g.://Peter sings//Petya mahnı oxuyur, and Peter sings beautifully// Petya gözal mahn oxuyur. Out of these two sentences the first one (//Peter sings//Petya mahnı oxuyur) both in the English and Azerbaijani sentences are simple sentences with two members, they consist of only the main members of the sentences. But in the second sentence the speaker had to express his/her thought more widely. For doing so, he/she had to use a new sentence member (beautifully) to express in what manner the action has been carried out. This syntactic construction, being different from the first one is considered as a simple-extended sentence. Since the sentence members which constitute its structure vary in terms of their quantity, their internal structure can also vary. The fact that in the both - English and Azerbaijani languages each of the sentence members entering the structure of the sentence is a different bearer of semantic and syntactic functions is not something a new thing. For e.g.:

1. He looked solicitously out of the window.

2. O, maraqla pəncərədən çölə baxd1.

3. O, səbirsizliklə ilk oğlu Mərdanın toyunu gözləyirdi.

Despite the fact that each of these sentences is a simple sentence, the sentence members entering the structures of these sentences are different.

The differences in the syntactic structures lie in the fact that in the first sentence while adverb of place is participating, but in the third sentence we don't see such a case. In the third sentence participation of attribute and object as sentence members differentiates the third sentence from the first one structurally. The common feature for the both structures is that in both of them, the main sentence members and adverb of manner are used. In the English variant of the sentence "He looked..." the adverb expressing the manner of action (solicitously) is used after the predicate. But in the Azerbaijani language the place of this sentence member is uncertain, because it has the character of changing its place within the structure of the sentence.

In the English language, in the structure of the simple sentence adverb of manner, while being used after the predicate 
of the sentence, in the Azerbaijani language it is used before the predicate. For e.g.:

1. The doctor said irritably.

2. Həkim əsəbi halda danışd1.

So, in the both languages sentence members are not distributed chaotically. Their distribution within the sentence is regulated by certain rules. Each of the sentence members, entering the sentence structure in the syntagmatic order, establishing coordination with sentence members coming before or after it, turns to the bearer of the intended semantic or grammatical functions. In the above-mentioned sentence adverb of manner by entering the predicate group, establishes semantic or syntactic coordination with the predicate and explains it. In the Azerbaijani language, the word (a sentence member) which is in semantic and syntactic coordination, with the adverb is situated to the right of it, but in the English language, visa-versa it is placed to the left of it. It is necessary to note that in the linguistic literature, in most cases instead of term "the order of distribution of sentence members" the term "word order" is used (Smirnitski, 1957, Musayev, 1996, Veyselli, 2003, etc.). But lately we come across the fact of protesting against the use of such a term. Words within a sentence are distributed as to the functions, which they carry out in the sentences. In the sentence level, the bearers of this function are called sentence members. That's why it's purposeful to use the term "the order of distribution of sentence members" instead of the usage of the term "word order in a sentence". In the English language, in the simple sentences, the word, indicating the adverb of manner, though is mainly used after the predicate, depending on what the adverb is expressed by, in its usage variation takes place.

\section{REFERENCES}

Abdullayev A., Seyidov Y., Hasanov A. (1972). Modern Azerbaijani Language. Baku: Maarif.

Budaqova Z. (1963). Simple Sentence in the Modern Azerbaijani language. Baku: Maarif.

Chládková, H. (1979). English and German equivalents of the Czech adverb of manner examined from the point of view of functional sentence perspective. Brno studies in English. 1979, vol. 13, pp. 61-104.

Diessel, H. (2001). The Ordering Distribution of Main and Adverbial Clauses: A Typological Study. Language, Vol. 77, No. 3, pp. 433-455.

Duskova, L. (2002), Syntactic constancy of adverbials between English and Czech. Acta UniversitatisCarolinae-Philologica 2 Prague Studies in English, XXIII, pp. 111-126.

Haider, H. (2000). Adverb placement - convergence of structure and licensing. Theoretical Linguistics, Vol. 26, pp. 95-134.

Eckart, R. (2003). Manner adverbs and information structure: Evidence from the adverbial modification of verbs of creation. In E. Lang, C. Maienborn and C. Fabricius-Hansen (Eds.) Modifying Adjuncts. Berlin: Mouton de Gruyter, pp. 365-305.

Fillmore, C. J. (1994). Under the Circumstances (Place, Time, Manner, etc.), Proceedings of the Twentieth An- nual Meeting of the Berkeley Linguistics Society: General Session Dedicated to the Contributions of Charles J. Fillmore, pp. 158-172.

Hasselgård, H. (2010) Adjunct Adverbials in English. Cambridge: CUP.

Hengeveld, K. (1997). Adverbs in Functional Grammar. In G. Wotjak (Ed.), Toward a functional lexicology: papers in honor of L. Martín Mingorance/Haciaunalexicologíafuncional (pp. 121-136). Frankfurt: Peter Lang.

Koktova, E. (1986). Sentence Adverbials in a Functional Description (Pragmatics \& Beyond). Amsterdam; Philadelphia: J. Benjamins.

López, A.I.O (1995). The distribution of adverbial phrases in English. Atlantis XVII 1-2:181-206.

Musayev O. (1996). Grammar of the English Language. Baku: Maarif.

Pezatti, E. G. (2007). Ordering of representional level adverbial modifiers in spoken Brazilian Portuguse. Alfa, São Paulo, 51 (2): 293-315.

Povolná, R. (2000). Some notes on spatial and temporal adverbials with regard to functional sentence perspective (based on conversational texts from LLC). Sbornikpraci Filozofické fakulty Brněnskéuniverzity, Řadaanglistická: Brno Studies in English 26, Brno: Masarykova univerzita v Brně, 2000, XLIX, No 6, p. 27-56. ISSN 1211-1791.

Tenny, C. (2000). Core events and adverbial modification. In J. Pustejovsky and C. Tenny (2000), Events as Grammatical Objects. Stanford: Center for Study of Language and Information, pp. 285-334.

Toratani, K. (2007). An RRG Analysis of Manner Adverbial Mimetics. Language and Linguistics, 8.1: 311-342.

Veysalli F. (2003). Introduction to the German linguistics. Baku: Tahsil.

Virtanen, T. (2008). Adverbials of 'Manner' and 'Manner Plus' in Written English: Why Initial Placement? SKY Journal of Linguistics, 21, 271-293.

Von Geuder, W. (2000). Issues in the Lexical Semantics of Event Adverbs. Philosophische Dissertation, angenommen von der Neuphilologischen Fakultät der Universität Tübingen.

Yang, T. (1999). Computational verb systems: averbs and adverbials as modifiers of verbs. Information Sciences, Volume 121, Issues 1-2, pp. 39-60.

Zareva, A. (2009). Informational packaging, level of formality, and the use of circumstance adverbials in L1 and L2 student academic presentations. Journal of English for AcademicPurposes, Volume 8, Issue 1, pp. 55-68.

\section{REFERENCES IN RUSSIAN}

Зиндер Л.Р. (1979). Общая фонетика.Москва:Высшая школа.

Смирницкий А.И. (1957). Синтаксис английского языка, Москва: Издательство.

Литературы На Иностранных Языках.

Шенделсь, Е. (1952). Грамматика немецкого языка. Москва: Издательство.

Литературы На Иностранных Языках. 